\title{
Management of Patient with Hypodontia: Review of Literature and Case Report
}

\author{
Nasrin R. Sadaqah', Jawad Abu Tair ${ }^{2}$ \\ ${ }^{1}$ Department of Prosthodontics, Faculty of Dentistry, Arab American University, Jenin, Palestinian Territory \\ ${ }^{2}$ Department of Surgery, Faculty of Dentistry, Arab American University, Jenin, Palestinian Territory \\ Email: na_sadaqa@yahoo.com
}

Received 28 October 2015; accepted 19 December 2015; published 22 December 2015

Copyright @ 2015 by authors and Scientific Research Publishing Inc.

This work is licensed under the Creative Commons Attribution International License (CC BY).

http://creativecommons.org/licenses/by/4.0/

(c) (i) Open Access

\begin{abstract}
Hypodontia is defined as the developmental absence of one or more teeth which can affect both the primary and permanent dentition. During the diagnosis procedure several other dental and oral symptoms can be observed. However esthetic and psychological problems require special attention for these patients, considering that they are often associated with low self-esteem and problems of social acceptance. The optimal therapy should include an interdisciplinary team approach. This review aimed to find out prevalence, causes, clinical manifestations, and treatment modalities of hypodontia. A case report describes that the treatment planning for a patient suffering from oligodontia is introduced at the end of the review. A specialist with the patient together made the decision regarding treatment.
\end{abstract}

\section{Keywords}

Hypodontia, Oligodontia, Missing Teeth, Full Mouth Rehabilitation, Treatment Options

\section{Introduction}

Hypodontia is defined as the developmental absence of one tooth or more which can affect primary and permanent dentition [1], generally:

- Hypodontia refers to the condition where there is absence of one or a few teeth only.

- Oligodontia is usually used to describe large numbers of missing teeth, six or more.

- Anodontia is the complete absence of teeth [2].

The etiology, prevalence, clinical manifestations associated with hypodontia and treatment modalities are re- 
viewed within this article. It is likely that the majority of patients with hypodontia will require a range of treatment modalities. Treatment of one case of hypodontia is described at the end of review.

\section{Etiology}

Missing teeth may be the result of numerous independent pathologic mechanisms that can cause one or more of the following [2]:

- Physical obstruction or disruption of the dental lamina.

- Space limitation.

- Functional abnormalities of the dental epithelium.

- Failure of initiation of the underlying mesenchyme.

The causes of missing teeth can be broadly classified into general and local.

1) General causes of hypodontia:

General including those cases where there is genetic cause so hypodontia may arise as a familial condition: a large proportion of affected individuals are members of families with a previous history of the condition [3].

Tooth development is a complex process involving multiple genes, which are also involved in the development of the craniofacial structures and structures of ectodermal origin [4]. Mutations of these genes can therefore have wider effects, and as a result hypodontia may occur as a feature of a number of syndromes including the ectodermal dysplasia (ED) [1] [4], Down's syndrome and chondroectodermal dysplasia [5] [6].

Brook [3] suggests that most cases of hypodontia have a polygenetic inheritance pattern and that the risk of relatives having hypodontia will depend on a combination of numerous genetic and environmental factors, each with a small effect.

Familial hypodontia is reported to exhibit mainly autosomal dominant inheritance with incomplete pentrance and variable expressivity [7]-[9]. It has also been suggested that it can follow sex-linked inheritance [3] [10] [11]. Using gene maping strategy autosomal dominant hypodontia has been localized to at least three chromosomal loci to date; MSX1 [12], PAX9 [13], and on unknown locus on chromosome 10 [14].

2) Local causes of hypodontia:

Local factors result in acquired hypodontia and can cause tooth agenesis by variety of means, that can be broadly divided into two groups: invasive and non invasive [15].

These factors can act either additively or independently to affect the positioning and physical development of the tooth.

Jaw fractures, surgical procedures, extraction of the preceeding primary tooth and changes in muscle pressure from the facial and lingual sides are all examples of invasive factors that can affect tooth development leading to tooth agenesis [16] [17].

It has been also shown that developing teeth are irreversibly affected by chemotherapy and irradiation in an age and dose dependent manner [18] [19], nutrient deprivation and serious illness have been also linked to tooth development problems, although no definite etiological relationship has been found between hypodontia and systematic disease [16]. Also hormonal and metabolic disturbances may affect teeth development [2].

It is known that not all teeth are equally affected by environmental factors [2]. The more distal a tooth for example lateral incisors and second premolars the more it seems to be influenced by environment [17]. However, the different development times of these two teeth, they are more likely to be influenced by genetic factors [2].

\section{The Prevalence of Hypodontai}

The prevalence of hypodontia in the primary dentition ranges from $0.08 \%$ to $1.55 \%$ [20]. In the permanent dentition, prevalence has been reported to range from $2.3 \%$ to $11.3 \%$ depending on the population investigated [2] [21] [22]. Hypodontia in the primary dentition has no significant sex distribution, but in the permanent dentition females are affected more frequently than males by a ratio of 3:2 [4].

Although not all reports are in agreement, it is generally accepted that excluding third permanent molars the second mandibular premolar is the most frequently missing permanent tooth representing $40 \%$ to $50 \%$ of the total number of developing missing teeth [23] [24]. Hypodontia affecting the maxillary lateral incisors is next in terms of frequency $25 \%$ and the mandibular central incisor $6.5 \%$ [23]. These four teeth account for $90 \%$ of absent teeth in hypodontia studies [23] [25]. 
In approximately $80 \%$ of reported cases of hypodontia only one or two teeth are missing; in $10 \%$ four or more teeth are missing, while in fewer than $1 \%$ six or more teeth are absent [4]. Permanent first premolars, first molars and canines are very rarely developmentally absent, their absence is usually associated with severe hypodontia or oligodontia [1].

There does appear to be a strong relationship between missing primary teeth and permanent successors [26]. The pattern of hypodontia however, is different: incisors missing in the primary dentition, premolars in the permanent and the numbers missing in the permanent dentition are always greater than in the primary dentition [26].

The prevalence of hypodontia in the maxillary arch is higher than in mandibular arch [27]-[29].

\section{Clinical Manifestations Associated with Hypodontia}

A number of features have been shown to be associated with hypodontia including both dental and craniofacial.

Dental findings:

1) The teeth are often microdontic or macrodontic, conical or tapered [30].

2) Eruption of permanent teeth may be delayed or abnormal [31]. [32].

3) If the maxillary lateral incisors are microdontic or absent, the maxillary canines may follow an ectopic path

4) The retained primary teeth may become infraoccluded, resulting in loss of space because of tilting of adjacent permanent teeth. Usually these retained teeth are ankylosed and their surgical and orthodontic implications must be considered [33].

5) The lack of teeth is often associated with developmental failure of alveolar bone resulting in an apparent atrophy of the ridge and lack of posterior support [30].

6) The teeth are associated with taurodontism: enlarged pulp chambers apical displacement of the bifurcation or trifurcation of roots [34].

7) Most of the cases are associated with maxillary sinuses pneumatisation [34].

8) The teeth may show structural problems such as hypocalcification and dentinogenesis imperfect [35].

Craniofacial findings:

Hypodontia may be associated with craniofacial features such as:

1) Retrognathic maxilla/protrusive mandible [34].

2) Reduced lower facial height with deep overbite and increased freeway space [36] [37].

In addition to the previously mentioned factors speech and masticatory disorders may also occur [38].

\section{Impact of Hypodontia on Patients}

The absence of teeth can seriously disable a young person both physically and emotionally, especially during the turbulent years of adolsence, the absence of teeth is a clinical and public health problem [39].

The patients in these conditions may present several signs and symptoms as reduction of the chewing ability, malocclusion, problems in articulating words, compromised esthetics, periodontal damage and alveolar bone deficiency. These complications may affect self-esteem, behavior patterns, and social life of these patients [39] [40].

\section{Factors Affecting Treatment Options for Patients with Hypodontia}

In general the options for treatment depend on the severity of hypodontia [30]. A number of factors must be taken into account at the time of treatment planning including:

1) Oral health and patient motivation:

The patients concerns and expectations of treatment are the most important driver for treatment. Complex treatment is likely to require attendance at numerous appointments over a lengthy period, as well as ongoing commitment to the maintenance of oral health and repeat treatment in the future. It is important that the patient understands this long-term picture and is prepared to take responsibility for their oral health [34].

In general severe hypodontia itself is not associated with a heightened caries risk unless it is seen as part of a 
syndrome, such as ectodermal dysplasia of which xerostomia is a feature [34]. Caries risk should be assessed since the most useful indication of future caries risk is previous caries experience [41].

2) Patient age:

Age is important factor in determining the type of treatment for hypodontic cases. When patients are in the primary and mixed dentition, treatment should be kept minimal and depending on patient's concerns it may be possible to avoid restorative intervention at this stage. Older children tend to become more conscious of their appearance, so the demand of treatment increases, and compliance for extensive dental treatment may also improve [42].

Depending on patient age one of the following types of treatment will be chosen:

- For patients younger than 6 years [patients with deciduous teeth] in case of severe hypodontia removable partial denture can be used to enhance psychological and functional conditions.

- Patients within 7 - 12 years (patients within mixed dentition) one of the following treatment options can be chosen:

a) Composite build ups to improve esthetics of microdont permanent teeth.

b) Removable partial denture.

c) Consider interceptive extractions to guide eruption.

d) Simple orthodontic treatment for space redistribution.

- Patients within 12 - 16 years (patients with permanent dentition) one of the following treatment options can be chosen:

a) Orthodontic treatment.

b) Resin bonded bridges following orthodontic treatment for teeth replacement.

c) Composite build ups for a microdont or hypoplastic teeth.

d) Overdentures for severe hypodontia.

- Patients within 16 - 20 years:

a) Single tooth implant or implant fixed bridges or implant retained overdenturs.

b) Orthodontic in combination with orthognathic surgery.

3) Position and quality of teeth present:

Where primary teeth are retained and have a reasonable prognosis, aesthetics may be improved significantly by the use of composite bonding [43].

Patients presenting a small number of missing teeth can be treated by adhesive restoration, fixed prosthesis, and dental implants. However, for patients with a large number of missing teeth the treatment choices should include overdentures supported by natural teeth or by osseointegrated implants, fixed prosthesis, or temporary/ definitive removable partial denture [44].

4) Skeletal patterns and soft tissue profile:

It is common in patients with hypodontia to see reduced lower face height [38], and some authors have reported a tendency toward a class III skeletal patterns, which increases with the severity of hypodontia [45]. A reduction in lip protrusion particularly of the upper lip has also been reported [46].

It is important to access these factors when planning restorative treatment as there may be a need to increase the lower face height and reorganize the occlusal scheme for both functional and aesthetic reasons [34].

5) Bone anatomy and position of vital structures:

In severe hypodontia patients, the absence of permanent results in restricted alveolar growth [47]. As a result there may be insufficient bone for provision of dental implants. Even where primary teeth are retained and immediate implant placement is possible there is often concavity of the alveolar process beyond the root apices, giving an (hour glass) ridge morphology in cross section.

\section{Treatment Modalities}

Treatment options will depend on the previously mentioned factors however, in all cases of hypodontia there are essentially four treatment options [48]:

1) Accept the situation with no intervention and provide maintenance.

2) Redistribute the spaces orthodontically or by elective extraction of primary teeth.

3) Maintain the space and resolve it by either dentures, bridges, tooth transplantation or implants. 
4) Use removable prosthesis to restore spaces.

Where there are edentulous spaces of short length it may be possible to place tooth supported bridge work, however the abutment teeth must be of sufficient quality. Primary molar teeth that are ankylosed or have reasonable root length can also act as abutments as they have good coronal surface area provided the occlusal surface is utilized for bonding [43]. Where implants are not possible, options for restoring many spaces and multiple missing teeth are generally limited to removable partial dentures, these can provide a predictable solution and are often better able to replace soft and hard tissue differences without recourse to invasive surgery [34].

The treatment goals are to keep the remaining teeth, recover function and esthetics, improve speech, and reestablish the emotional and psychological well-being [2] [49]. Regarding prosthetic treatment its objective include restoring the masticatory function, maintaining the position of adjacent natural teeth, preventing undesirable movements, improving esthetics, avoiding social problems to the patient and replacing the missing teeth without interfering in the growth of the mandible and maxilla [50].

\section{Case Report}

A 21-year-old girl presented as a new patient upon referral from her dentist to the Department of Prosthodontics, Faculty of Dentistry, Arab American University, Jenin. Her chief complain was esthetic involvement caused by absence of lower central and lateral incisors and excessive spacing between upper anterior teeth. Written informed consent was obtained from the patient for treatment and publication of this case report.

A thorough medical and dental history was taken at the first appointment, which revealed no classical syndrome features, such as ectodermal dysplasia associated with missing teeth. Family history revealed that her brothers, sister, and uncles are suffering hypodontia, and these findings highlighted the hereditary conditions that may predispose hypodontia [2]. It is known that hypodontia has a genetic basis and other family members are often affected.

During intraoral examination the absence of 18 permanent teeth was noticed, including maxillary lateral incisors and canines, maxillary right and left second premolars, maxillary right first molar and second molar, mandibular central and lateral incisors and canines, second premolars and second molars. Maxillary and mandibular primary canines were present. Regarding soft tissue the maxillary labial frenum was enlarged, oral hygiene was considered satisfactory and no previous dental treatment was performed. The patient presented upper excessive spaces between teeth, and deep overbite with increased freeway space. The patient reported severe esthetic dissatisfaction which resulted in several social problems (Figure 1 and Figure 2).

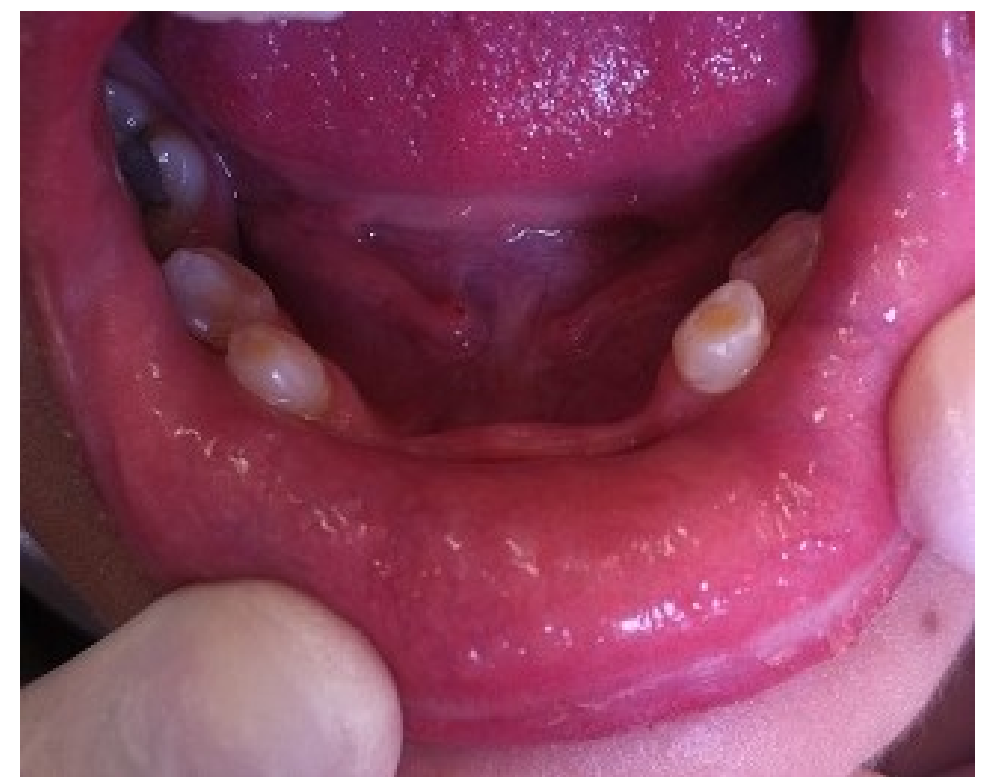

Figure 1. Intra oral preoperative view of lower arch. 


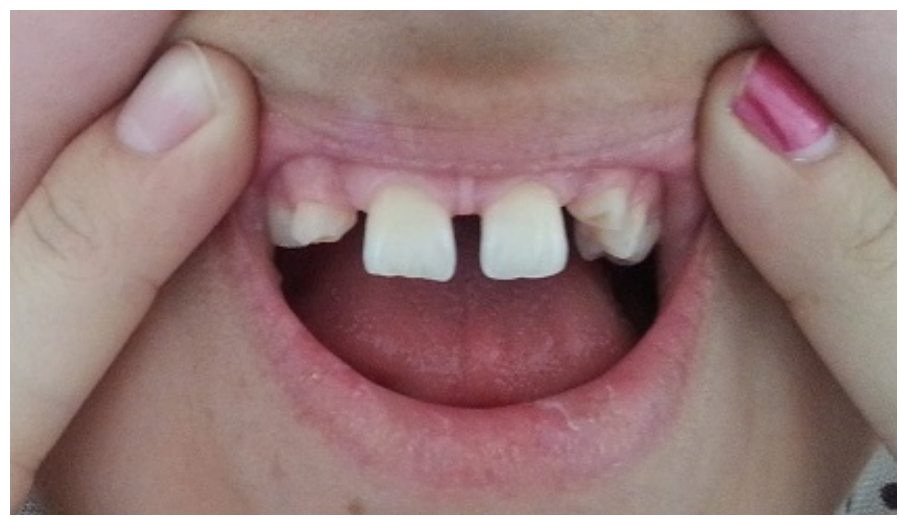

Figure 2. Intra oral preoperative view of upper arch.

Extraoral clinical examination revealed a mild reduction in lower third of facial height with a marked nasolabial angle (Figure 3).

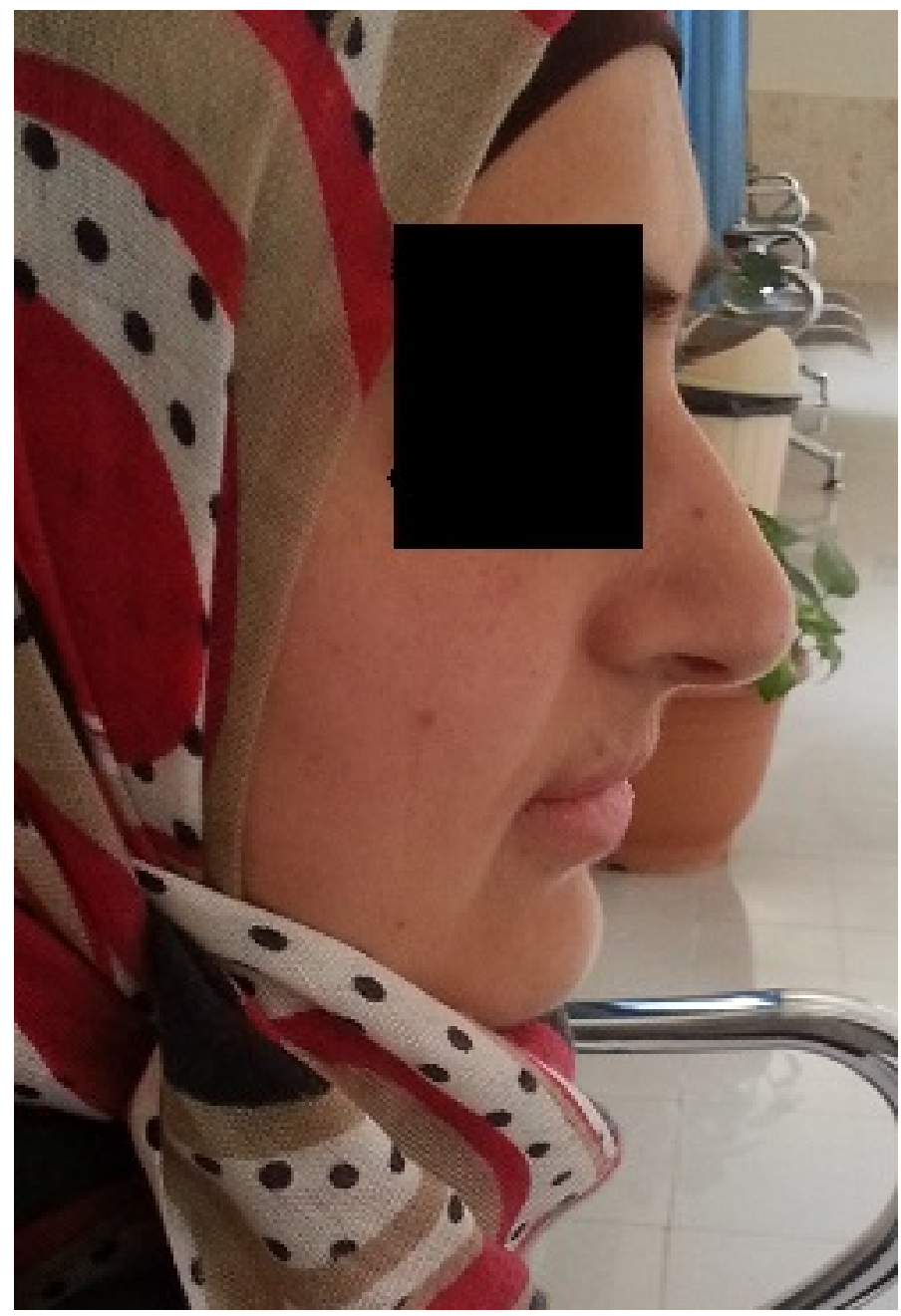

Figure 3. Extra oral preoperative view.

Panoramic radiographic examination showed no osseous lesions and a dense alveolar bone, the retained primary canines revealed no root resorption and absence of permanent successors. 
After careful interview, clinical examination, and radiographic analysis a diagnosis of oligodontia was confirmed and a multidisciplinary treatment approach was planned.

An initial discussion with the patient about the feasible treatment options from the ideal to the least ideal choice, along with an explanation of the advantages and disadvantages of each option, was undertaken as follows:

- Orthodontic treatment to redistribute the spaces in the upper arch and restoring of missing teeth in upper and lower arches using implants and recontouring of the remaining teeth by composite restoration.

- Orthodontic treatment to redistribute the spaces in the upper arch and restoring the missing teeth using fixed prosthesis in upper and lower jaws.

- Restoring the missing teeth using fixed prosthesis and simultaneously readjustment of remaining teeth shape.

The patient refused to undergo any orthodontic and surgical treatment due to financial and time constrains, she preferred fixed peosthesis as a treatment option excluding other modalities.

Primary impressions using alginate (Orthoprint, Zhermark Inc, Eatontwon, NJ) and wax occlusal records were taken to make articulated models. The diagnostic casts were duplicated using light viscosity additional silicone impression material (Elite Model, Zhermark Inc) and the impressions were poured using dental stone (Elite Rock, Zhermark Inc). Afterwards a completed diagnostic preparation of abutments and wax up of teeth (S-UShade-Set wax, Number 5 Intensive-white Schuler-Dental, Ulm, Germany) was undertaken taking into consideration increasing the vertical dimension of occlusion without affecting normal freeway space (Figure 4 and Figure 5).

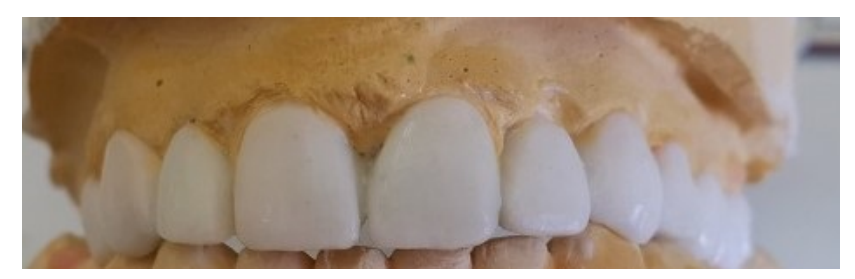

Figure 4. View for the upper arch diagnostic wax up.

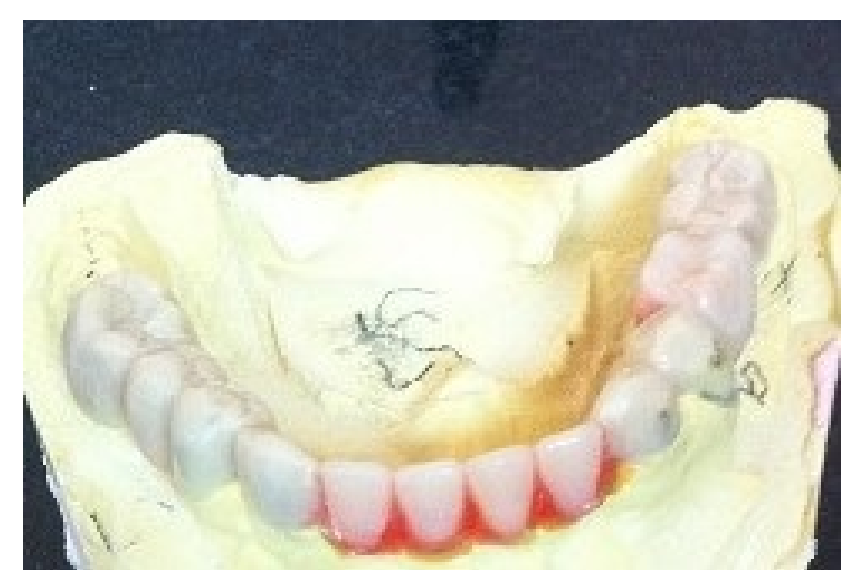

Figure 5. View for the lower arch diagnostic wax up.

The diagnostic wax up of the proposed fixed bridges were duplicated using light viscosity addition silicone impression material (Elite Model). The impressions were then poured in dental stone (Elite Rock), and a silicone indices (Hydrorise Heavy, Zhermack Inc.) were fabricated on this new duplicated casts.

After analyzing the diagnostic wax up and the amount of tooth preparation needed to align the teeth in a relatively acceptable esthetic and functional relationship, it was decided to undertake elective root canal treatment for the maxillary central incisors and primary canines and mandibular second molars. Also it was decided to go for crown lengthening surgery for the upper jaw so that to realign the gingival line to be parallel to interpupillary line anteriorly and the ala tragus line posteriorly, furthermore frenectomy for enlarged upper labial frenum was also needed (Figure 6). 


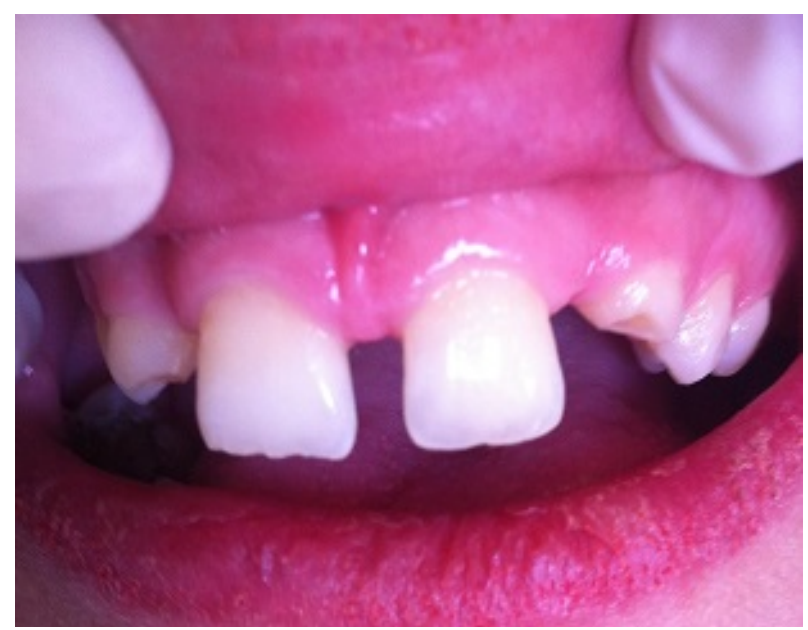

Figure 6. Intra oral view showing preoperative giniva and labial frenum.

The maxillary centrals, primary canines and mandibular second molars were endodontically treated and cast post and cores were fabricated for maxillary primary canines and prefabricated posts (Figure 7) and composite cores for maxillary centrals.

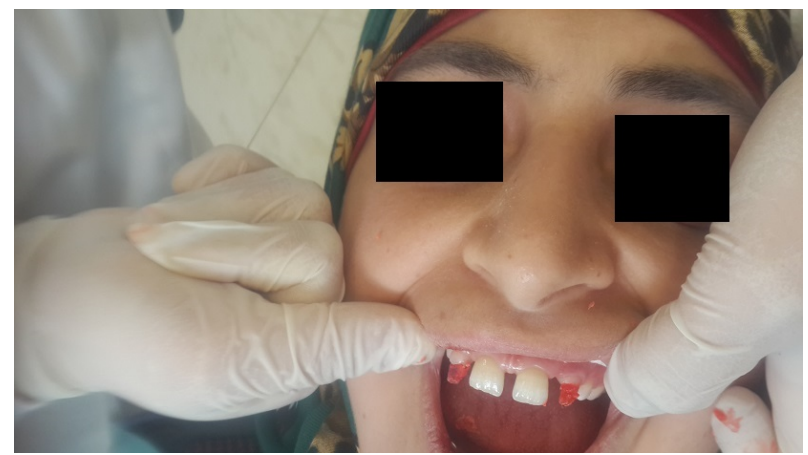

Figure 7. Intraoral view for duraly impression for cast posts and cores.

Subsequently all teeth were prepared in a conventional manner using diamond burs. Margins were $1.2 \mathrm{~mm}$ width and placed $1.0 \mathrm{~mm}$ subgingivally (Figure 8).

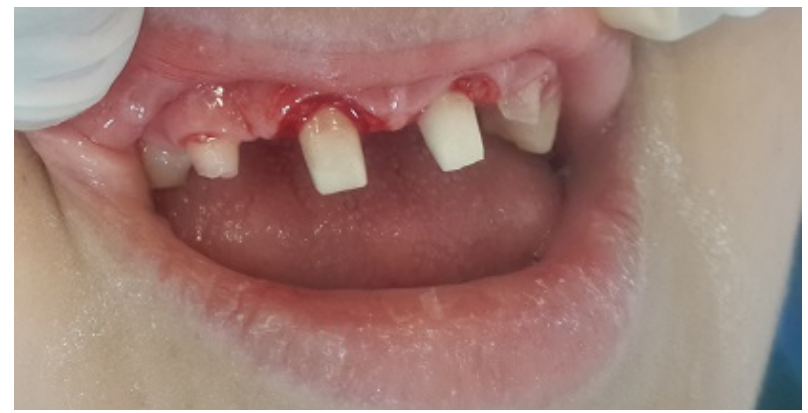

Figure 8. Intraoral view for teeth preparation.

Alginate (Orthoprint) impressions of the prepared teeth were taken and poured using stone (Elite Rock) to check up the preparation and to fabricate temporary bridges. 
The silicone indices made on duplicated casts of diagnostic wax up were placed on casts of the prepared teeth to verify the adequacy of teeth preparation for porcelain fused to metal restoration and then to make temporary bridges. The casts were coated with a separating medium (COE SEP GC Lab Technologies Inc, Lockport, IL), then a tooth colored acrylic resin (Jet Repair Acrylic, Lang Dental Manufacturing Co, Wheeling, IL) was mixed and placed in indices and positioned on casts (Figure 9 and Figure 10).

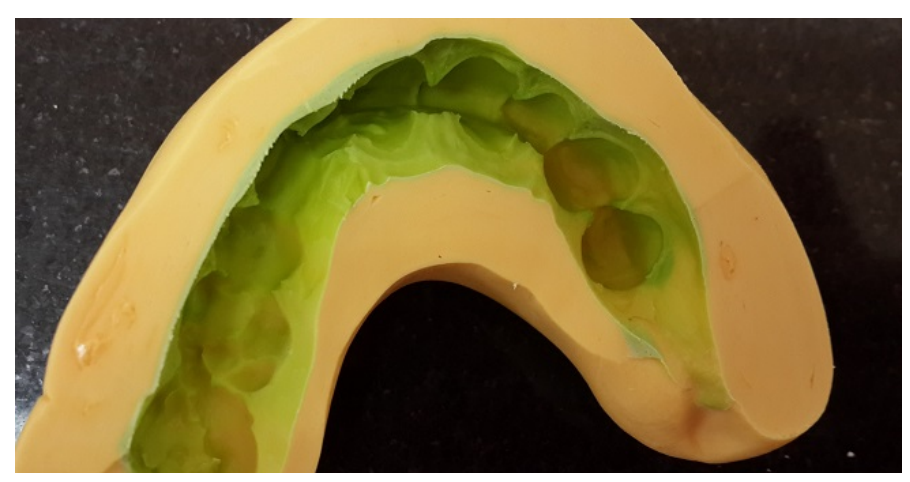

Figure 9. Index fabrication.

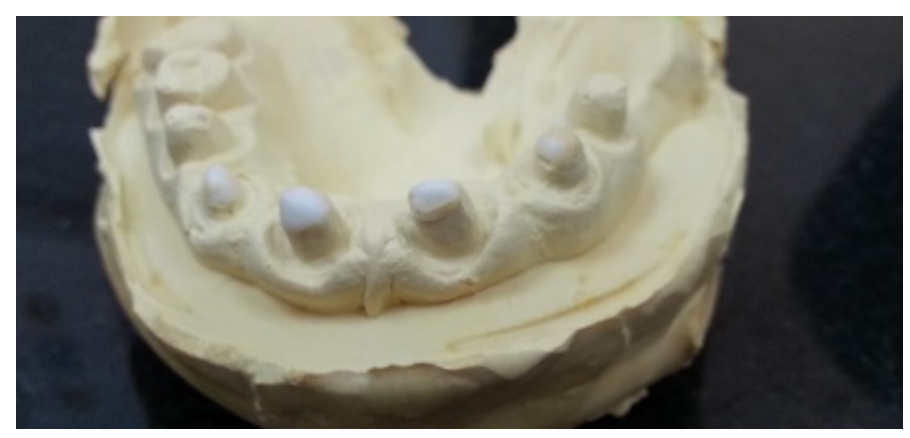

Figure 10. Upper diagnostic cast of prepared teeth for temporary fabrication.

When the resin was set the index and temporary bridges were removed from casts, the temporary bridges were finished, polished and tried in patient's mouth to verify fit, marginal adaptation, and occlusion was equilibrated to the new vertical dimension of occlusion. Temporary bridges were cemented using zinc oxide eugenolbased temporary cement (TempBond, Kerr Corporation, Orange, CA) (Figure 11 and Figure 12).

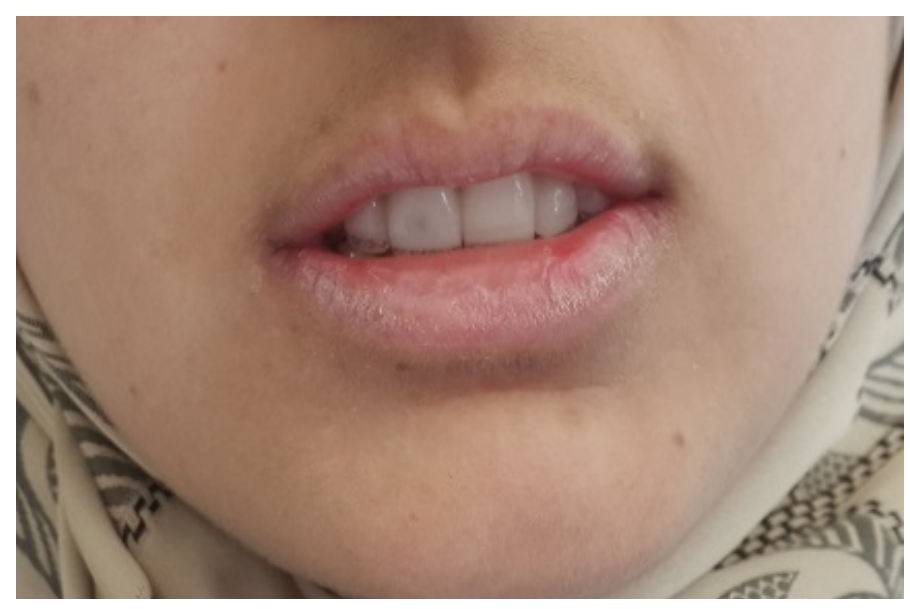

Figure 11. Temporary bridges cemented in patient’s mouth. 


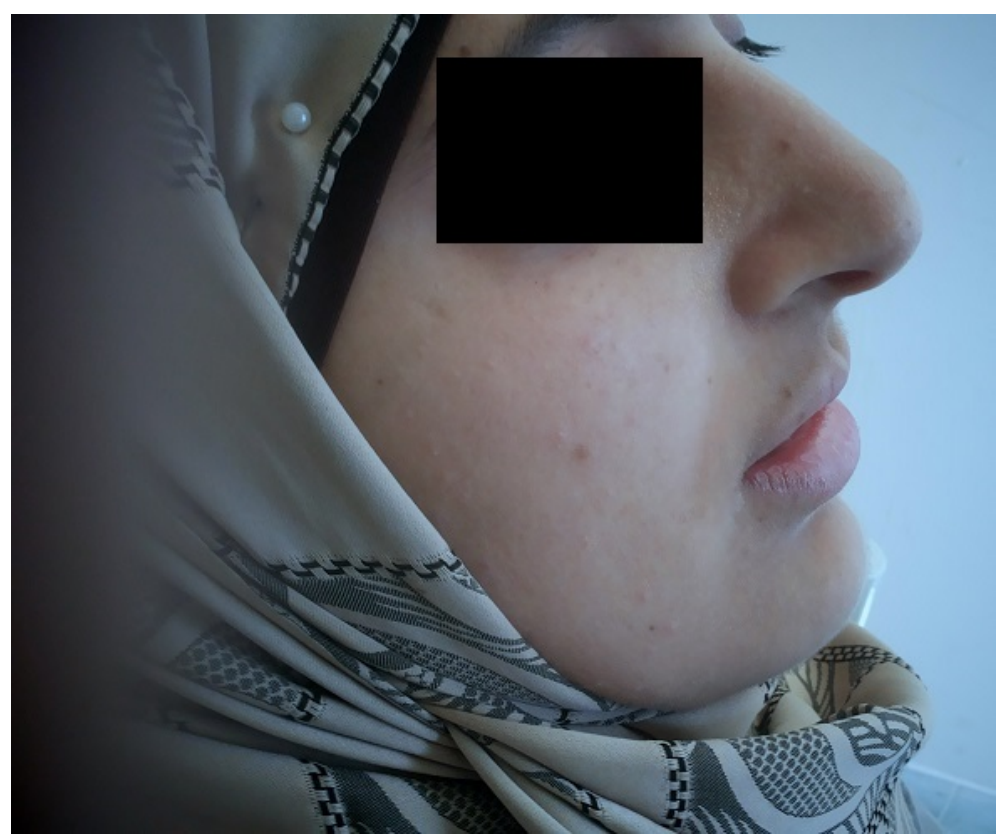

Figure 12. Lateral view for patient with cemented temporary bridges, the lower facial height was increased and naso-labial angle was reduced.

Frenectomy for upper labial frenum and crown lengthening for maxillary teeth were performed using surgical stent depending on the diagnostic wax up to realine the gingiva, the temporary bridge was readjusted and cemented using temporary cement, a periodontal back was adjusted on gingival tissue (Figures 13-16).

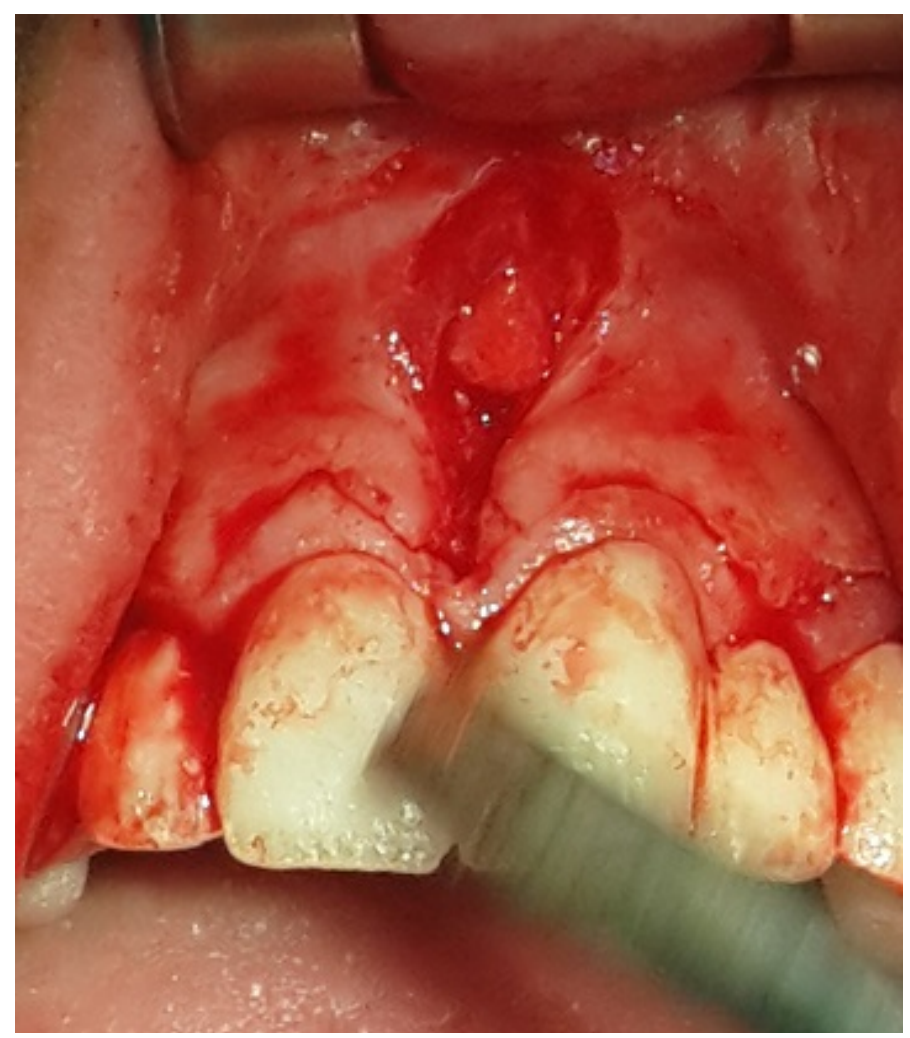

Figure 13. Frenectomy. 


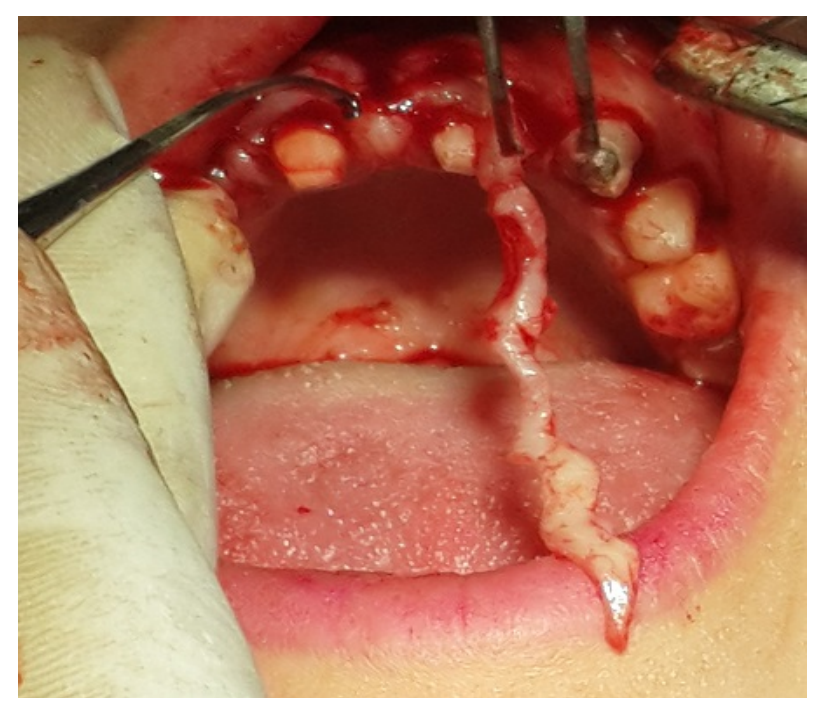

Figure 14. Crown lengthening.

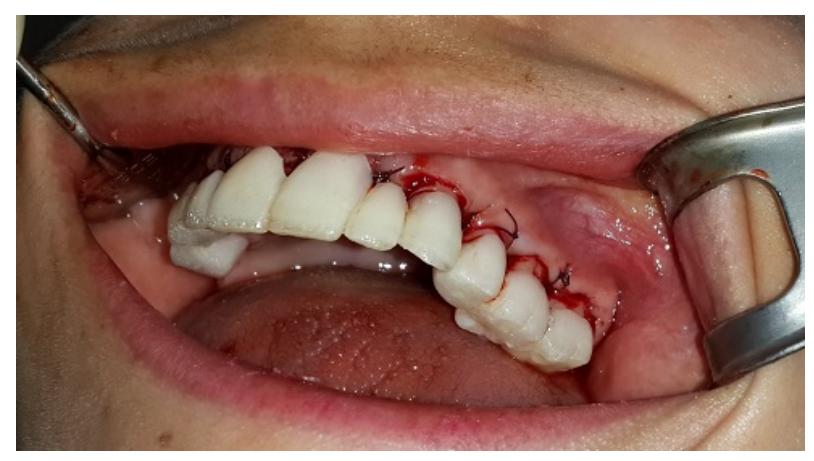

Figure 15. Temporary bridge in place after crown lengthening and before adjustment.

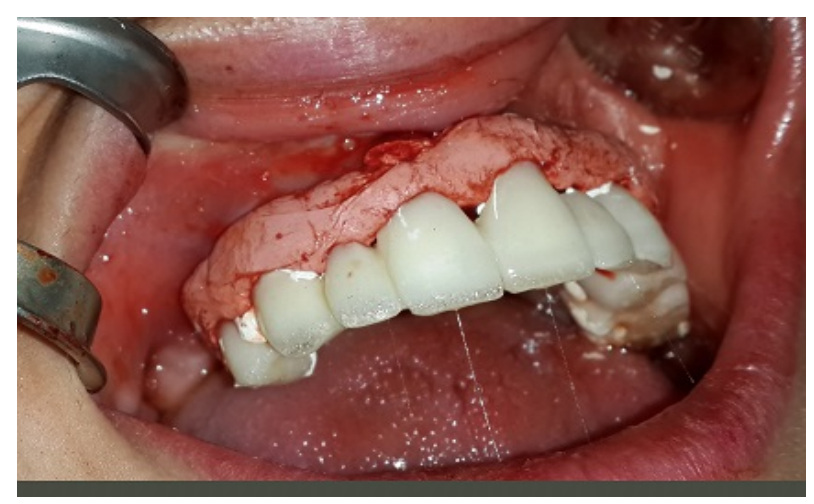

Figure 16. Temporary bridge in place after adjustment with periodontal back.

After six months teeth preparation was refined and final impressions of prepared teeth were taken using double-stage technique, using heavy and light body polyvinylsiloxane impression material (Hydrorise Heavy and Wash, Zhermark Inc). The casting try in was made one week after impressions were made, and the completed porcelain fused to metal bridges were cemented using TempBond after another one week. Definitive cementation was performed using glass ionomer cement (GC Fuji I, GC America Inc, Alsop, IL) after one month (Figures 17-21). 


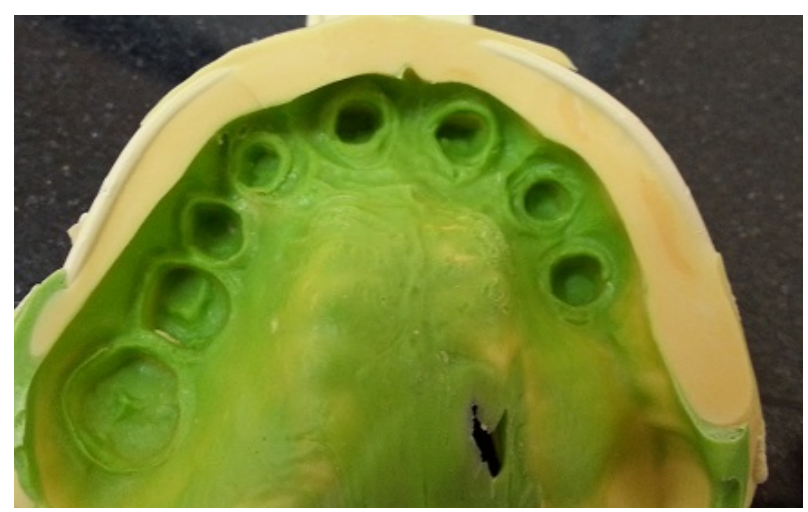

Figure 17. Upper secondary impression.

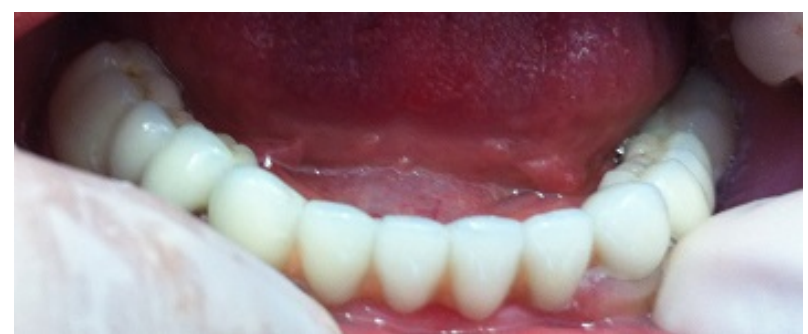

Figure 18. Definitive lower bridge after permanent cementation.

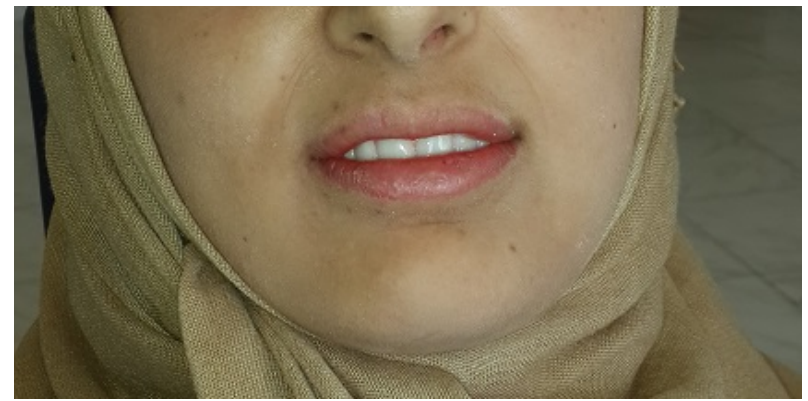

Figure 19. Definitive upper bridge after permanent cementation.

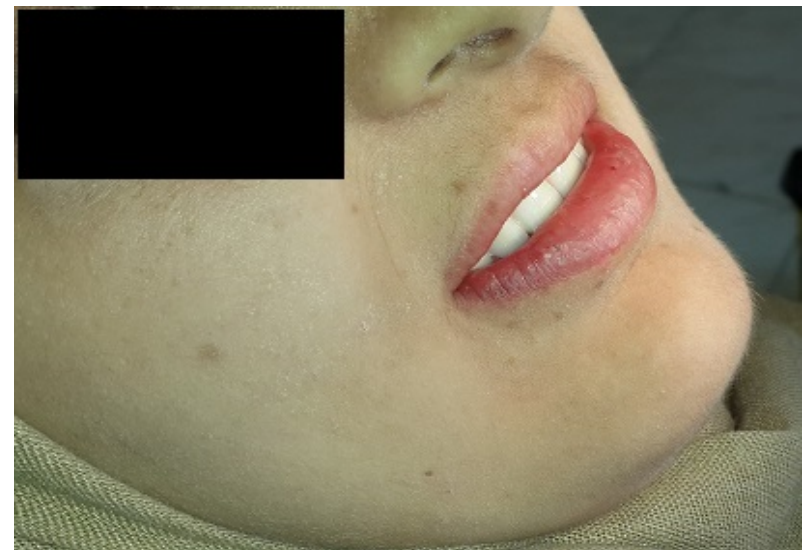

Figure 20. Extroral view after cementation of permanent bridges. 


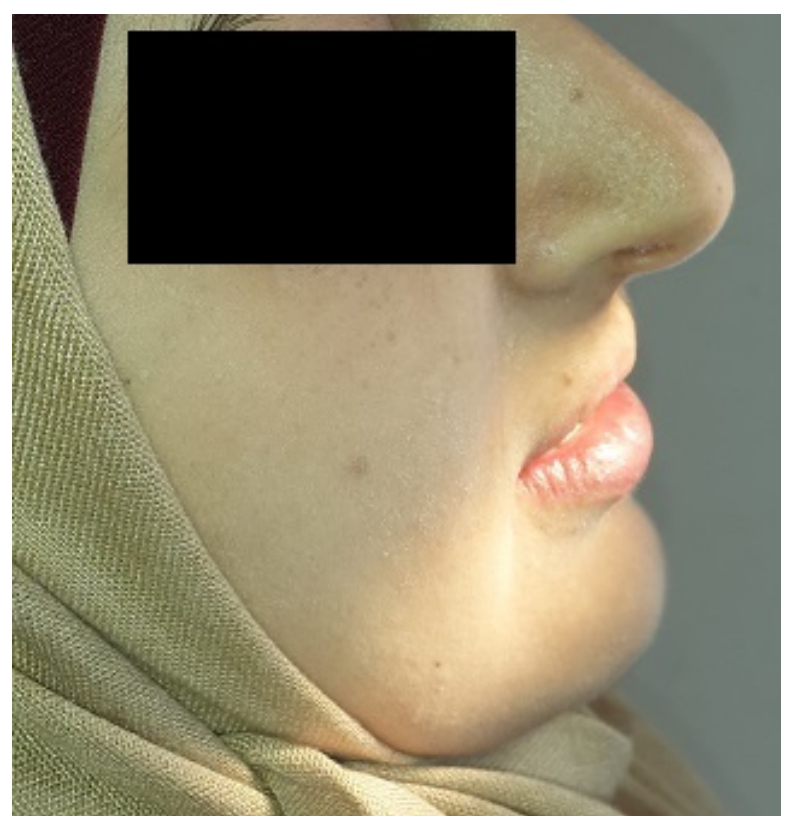

Figure 21. Extraoral lateral view after cementation of permanent bridges.

\section{Discussion}

The congenital absence of teeth may occur as an isolated condition or may be associated with systematic condition or syndrome. The dental and radiographic examinations are the best way to detect anomalies in primary and permanent dentition. In case of oligodontia treatment should be performed to restore masticatory function and aesthetics regardless of age or missing teeth, avoiding social problems to the patient especially in adolescence and restoring the missing teeth [2].

In the present case report the patient refused to go through lengthy treatment plan, so the treatment was done using teeth supported fixed prosthesis. To reestablish natural crowns ratios diagnostic wax up was critical, the wax up provided a matrix for fabrication of provisional restoration and also a blueprint for dental positioning and adjustment of the axes of the teeth [51].

Using the provisional restoration both patient and dentist had a second opportunity to test the restoration design after the diagnostic wax up. The provisional restoration was used to show the patient how this kind of restoration behaves and to obtain patient approval before definitive restoration is fabricated [52].

The final fixed prosthesis was fabricated with teeth in their ideal position. Ideal teeth relationship principles were used to position teeth in normal relationship.

In this clinical case after the cementation of final prosthesis even the external patient profile was changed, the lower face height was increased, the nasolabial angle was reduced, and the final result met patients expectations.

This case of an adolescent female who presented with oligodontia illustrates the importance of an accurate diagnosis and effective treatment plan that relies on appropriate discussion among the dental working team and patient.

\section{Conclusion}

The effective management of Oligodontia is likely to require the input of multiple clinicians. When teeth are missing conventional fixed prosthodontics can offer excellent option for the restoration of esthetics and function and are the most appropriate treatment modality for some patients.

\section{References}

[1] Hobkirk, J.A. and Brook, A.H. (1980) The Management of Patients with Severe Hypodontia. Journal of Oral Rehabil- 
itation, 7, 289-298. http://dx.doi.org/10.1111/j.1365-2842.1980.tb00447.x

[2] Nunn, J.H., Carter, N.E., Gillgrass, T.J., Hobson, R.S., Jepson, N.J., Meechan, J.G. and Nohl, F.S. (2003) The Interdisciplinary Management of Hypodontia: Background and Role of Paediatric Dentistry. British Dental Journal, 194, 245251. http://dx.doi.org/10.1038/sj.bdj.4809925

[3] Brook, A.H. (1984) A Unifying Aetiological Explanation for Anomalies of Human Tooth Number and Size. Archives of Oral Biology, 29, 373-378. http://dx.doi.org/10.1016/0003-9969(84)90163-8

[4] Larmour, C.J., Mossey, P.A., Thind, B.S., Forgie, A.H. and Stirrups, D.R. (2005) Hypodontia-A Retrospective Review of Prevalence and Etiology. Part I. Quintessence International, 36, 263-270.

[5] Gorlin, R.J., Pindorg, J.J. and Cohen, M.M. (1976) Syndromes of the Head and Neck. 2nd Edition, McGraw-Hill, New York.

[6] Winter, G.B. and Geddes, M. (1967) Oral Manifestations of Chondroectodermal Dysplasia (Ellis-Van Creveld Syndrome). Report of a Case. British Dental Journal, 122, 103-107.

[7] Arte, S., Nieminen, P., Apajalahti, S., Haavikko, K., Thesleff, I. and Pirinen, S. (2001) Characteristics of Incisor-Premolar Hypodontia in Families. Journal of Dental Research, 80, 1445-1450. http://dx.doi.org/10.1177/00220345010800051201

[8] Philip, M.J. and Caurdy, J.C. (1985) Inheritance of Hypodontia in Consanguineous Families of Arabic Decent. Ann Dent, 44, 39-41.

[9] Tal, H. (1981) Familial Hypodontia in the Permanent Dentition: A Case Report. Journal of Dentistry, 9, 260-264. http://dx.doi.org/10.1016/0300-5712(81)90067-1

[10] Peck, L., Peck, S. and Attia, Y. (1993) Maxillary Canine-First Premolar Transposition, Associated Dental Anomalies and Genetic Basis. Angle Orthodontist, 63, 99-109.

[11] Dahlberg, A.A. (1937) Inherited Congenital Absence of Six Incisors, Deciduous and Permanent. Journal of Dental Research, 16, 59-62. http://dx.doi.org/10.1177/00220345370160011001

[12] Vastardis, H., Karimbux, N., Guthua, S.W., Seidman, J.G. and Seidman, C.E. (1996) A Human MSX1 Homeodomain Missense Mutation Causes Selective Tooth Agenesis. Nature Genetics, 13, 417-421. http://dx.doi.org/10.1038/ng0896-417

[13] Stockton, D.W., Das, P., Goldenberg, M., D’Souza, R.N. and Patel, P.I. (2000) Mutation of PAX9 Is Associated with Oligodontia. Nature Genetics, 24, 18-19. http://dx.doi.org/10.1038/71634

[14] Liu, W., Wang, H., Zhao, S., Zhao, W., Bai, S., Zhao, Y., Xu, S., Wu, C., Huang, W., Chen, Z., Feng, G. and He, L. (2001) The Novel Gene Locus for Agenesis of Permanent Teeth (He-Zhao Deficiency) Maps to Chromosome 10q11.2. Journal of Dental Research, 80, 1716-1720. http://dx.doi.org/10.1177/00220345010800080701

[15] Riesenfield, A. (1970) The Effect of Environmental Factors on Tooth Development: An Experimental Investigation. Acta Anatomica, 77, 188-215. http://dx.doi.org/10.1159/000143541

[16] Grahnen, H. (1956) Hypodontia in the Permanent Dentition. A Clinical and Genetical Investigation. Odontologisk Revy, 7, 1-100.

[17] Schalk-van der Weide, Y., Steen, W.H. and Bosman, F. (1992) Distribution of Missing Teeth and Tooth Morphology in Patients with Oligodontia. ASDC Journal of Dentistry for Children, 59, 133-140.

[18] Maguire, A., Craft, A.W., Evans, R.G., Amineddine, H., Kernahan, J., Macleod, R.I., Murray, J.J. and Welbury, R.R. (1987) The Long-Term Effects of Treatment on the Dental Condition of Children Surviving Malignant Disease. Cancer, 60, 2570-2575. http://dx.doi.org/10.1002/1097-0142(19871115)60:10<2570::AID-CNCR2820601037>3.0.CO;2-Q

[19] Näsman, M., Forsberg, C.M. and Dahllöf, G. (1997) Long-Term Dental Development in Children after Treatment for Malignant Disease. European Journal of Orthodontics, 19, 151-159. http://dx.doi.org/10.1093/ejo/19.2.151

[20] Whittington, B.R. and Durward, C.S. (1996) Survey of Anomalies in Primary Teeth and Their Correlation with the Permanent Dentition. The New Zealand Dental Journal, 92, 4-8.

[21] McKeown, H.F., Robinson, D.L., Elcock, C., Al-Sharood, M. and Brook, A.H. (2002) Tooth Dimensions in Hypodontia Patients, Their Unaffected Relatives and a Control Group Measured by a New Image Analysis System. European Journal of Orthodontics, 24, 131-141. http://dx.doi.org/10.1093/ejo/24.2.131

[22] O’Dowling, I.B. and McNamara, T.G. (1990) Congenital Absence of Permanent Teeth among Irish School-Children. Journal of the Irish Dental Association, 36, 136-138.

[23] Rose, J.S. (1966) A Survey of Congenitally Missing Teeth, excluding Third Molars in 6000 Orthodontic Patients. The Dental Practitioner and Dental Record, 17, 107-114.

[24] Aasheim, B. and Ogaard, B. (1993) Hypodontia in 9-Year Old Norwegians Related to Need of Orthodontic Treatment. 
Scandinavian Journal of Dental Research, 101, 257-260. http://dx.doi.org/10.1111/j.1600-0722.1993.tb01115.x

[25] Rolling, S. (1980) Hypodontia of Permanent Teeth in Danish Schoolchildren. Scandinavian Journal of Dental Research, 88, 365-369. http://dx.doi.org/10.1111/j.1600-0722.1980.tb01240.x

[26] Daugaard-Jensen, J., Nodal, M., Skovgaard, L.T. and Kjer, I. (1997) Comparison of the Pattern of Agenesis in the Primary and Permanent Dentitions in a Population Characterized by Agenesis in the Primary Dentition. International Journal of Paediatric Dentistry, 7, 143-148. http://dx.doi.org/10.1046/j.1365-263X.1997.00230.x

[27] Vahid-Dastjerdi, E., Borzabadi-Farahnai, A., Mahdian, M. and Amini, N. (2010) Non-Syndromic Hypodontia in an Iranian Orthodontic Population. Journal of Oral Science, 52, 455-461. http://dx.doi.org/10.2334/josnusd.52.455

[28] Acharya, P.N., Jones, S.P., Moles, D., Gill, D. and Hunt, N.P. (2010) A Cephalometric Study to Investigate the Skeletal Relationships in Patients with Increasing Severity of Hypodontia. The Angle Orthodontist, 80, 511-518. http://dx.doi.org/10.2319/072309-411.1

[29] Celikoglu, M., Kazanci, F., Miloglu, O., Oztek, O., Kamak, H. and Ceylan, I. (2010) Frequency and Characteristics of Tooth Agenesis among an Orthodontic Patient Population. Medicina Oral Patologia Oral y Cirugia Bucal, 15, 797801. http://dx.doi.org/10.4317/medoral.15.e797

[30] Dhanrajani, P.J. (2002) Hypodontia: Etiology, Clinical Features, and Management. Quintessence International, 33, 294-302.

[31] Schalk-van der Weide, Y., Prahl-Andersen, B. and Bosman, F. (1993) Tooth Formation in Patients with Oligodontia. The Angle Orthodontist, 63, 31-37.

[32] Brin, I., Becker, A. and Shalhav, M. (1986) Position of the Maxillary Permanent Canine in Relation to Anomalous or Missing Permanent Lateral Incisors. A Population Study. European Journal of Orthodontics, 8, 12-16. http://dx.doi.org/10.1093/ejo/8.1.12

[33] Kurol, J. (1984) Infraocclusion of Primary Molars-An Epidemiological, Familial Longitudinal Clinical and Histological Study. Swedish Dental Journal, 21, 1-67.

[34] Durey, K., Cook, P. and Chan, M. (2014) The Management of Severe Hypodontia. Part 1: Considerations and Conventional Restorative Options. British Dental Journal, 216, 25-29. http://dx.doi.org/10.1038/sj.bdj.2013.1236

[35] Ahmad, W., Brancolini, V., ul Faiyaz, M.F., Lam, H., ul Haque, S., Haider, M., et al. (1998) A Locus for Autosomal Recessive Hypodontia with Associated Dental Anomalies Maps to Chromosome 16q12.1. The American Journal of Human Genetics, 62, 987-991. http://dx.doi.org/10.1086/301799

[36] Worsaae, N., Jensen, B.N., Holm, B. and Holsko, J. (2007) Treatment of Severe Hypodontia-Oligodontia-An Interdisciplinary Concept. Journal of Oral and Maxillofacial Surgery, 36, 473-480. http://dx.doi.org/10.1016/j.ijom.2007.01.021

[37] Kirzioglu, Z., Koseler Sentut, T., Ozay Erturk, M.S. and Karayilmaz, H. (2005) Clinical Features of Hypodontia and Associated Dental Anomalies: A Retrospective Study. Oral Diseases, 11, 399-404. http://dx.doi.org/10.1111/j.1601-0825.2005.01138.x

[38] Bural, C., Oztas, E., Ozturk, S. and Bayraktar, G. (2012) Multidisciplinary Treatment of Non-Syndromic Oligodontia. European Journal of Dentistry, 6, 218-226.

[39] Agarwal, P., Vinuth, D.P., Dube, G. and Dube, P. (2013) Nonsyndromic Tooth Agenesis Patterns and Associated Developmental Dental Anomalies: A Literature Review with Radiographic Illustrations. Minerva Stomatologica, 62, 31-41.

[40] Kulkarni, M., Agrawal, T. and Kheur, S. (2011) Tooth Agenesis: Newer Concept. The Journal of Clinical Pediatric Dentistry, 36, 65-70. http://dx.doi.org/10.17796/jcpd.36.1.p74362q544210p33

[41] Zero, D., Fontana, M. and Lennon, A.M. (2001) Clinical Applications and Outcomes of Using Indicators of Risk in Caries Management. Journal of Dental Education, 65, 1126-1132.

[42] Hobkirk, J.A., Goodman, J.R. and Jones, S.P. (1994) Presenting Complaints and Findings in a Group of Patients Attending a Hypodontia Clinic. British Dental Journal, 177, 337-339. http://dx.doi.org/10.1038/sj.bdj.4808606

[43] Robinson, S. and Chan, M. (2009) New Teeth from Old: Treatment Options for Retained Primary Teeth. British Dental Journal, 207, 315-320. http://dx.doi.org/10.1038/sj.bdj.2009.855

[44] Thalji, G.N. and Cooper, L.F. (2010) The Role of Complete Overdentures in Esthetic Rehabilitation of the Adolescent Oligodontia Patient. A Case Report. Journal of Esthetic and Restorative Dentistry, 22, 213-221. http://dx.doi.org/10.1111/j.1708-8240.2010.00341.x

[45] Chung, L.K., Hobson, R.S., Nunn, J.H., Gordon, H. and Carter, N.E. (2000) An Analysis of the Skeletal Relationships in a Group of Young People with Hypodontia. Journal of Orthodontics, 27, 315-318. http://dx.doi.org/10.1093/ortho/27.4.315

[46] Ogaard, B. and Krogstad, O. (1995) Craniofacial Structure and Soft Tissue Profile in Patients with Severe Hypodontia. 
American Journal of Orthodontics and Dentofacial Orthopedics, 108, 472-477. http://dx.doi.org/10.1016/S0889-5406(95)70047-1

[47] Bondarets, N. and McDonald, F. (2000) Analysis of the Vertical Facial Form in Patients with Severe Hypodontia. American Journal of Physical Anthropology, 111, 177-184. http://dx.doi.org/10.1002/(SICI)1096-8644(200002)111:2<177::AID-AJPA4>3.0.CO;2-8

[48] Hobson, R.S., Carter, N.E., Gillgrass, T.J., Jepson, N.J.A., Meechan, J.G., Nohl, F. and Nunn, J.H. (2003) The Interdisciplinary Management of Hypodontia: The Relationship between an Interdisciplinary Team and the General Dental Practitioner. British Dental Journal, 194, 479-482. http://dx.doi.org/10.1038/sj.bdj.4810184

[49] Derbanne, M.A., Sitbon, M.C., Landru, M.M. and Naveau, A. (2010) Case Report: Early Prosthetic Treatment in Children with Ectodermal Dysplasia. European Archives of Paediatric Dentistry, II, 301-305. http://dx.doi.org/10.1007/BF03262768

[50] Goncalves, T.M.S.V., Goncalves, L.M., Sabino-Bezerra, J.R., Santos-Silva, A.R., Silva, W.J. and Garcia, R.C.M.R. (2013) Multidisciplinary Therapy of Extensive Oligodontia: A Case Report. Brazilian Dental Journal, 24, 174-178. http://dx.doi.org/10.1590/0103-6440201302158

[51] Salama, M., Coachman, C., Garber, D., Calamita, M., Salama, H. and Cabral, G. (2009) Prosthetic Gingival Reconstruction in the Fixed Partial Reconstruction. Part 2: Diagnosis and Treatment Planning. International Journal of Periodontics \& Restorative Dentistry, 29, 573-582.

[52] Coachman, C., Salama, M., Garber, D., Calamita, M., Salama, H. and Cabral, G. (2010) Prosthetic Gingival Reconstruction in the Fixed Partial Restorations. Part 3: Laboratory Procedures and Maintenance. International Journal of Periodontics \& Restorative Dentistry, 30, 19-29. 